\title{
Cost-Effectiveness of Telemedicine in Remote Orthopedic Consultations: Randomized Controlled Trial
}

Astrid Buvik $^{1}$, MD; Trine S Bergmo ${ }^{2}, \mathrm{PhD}$; Einar Bugge ${ }^{3}, \mathrm{MD}, \mathrm{PhD}$; Arvid Smaabrekke ${ }^{1}, \mathrm{MD}$; Tom Wilsgaard ${ }^{3,4}$, $\mathrm{PhD}$; Jan Abel Olsen ${ }^{4,5}$, PhD

\footnotetext{
${ }^{1}$ Department of Orthopaedic Surgery, University Hospital of North Norway, Troms $\varnothing$, Norway

${ }^{2}$ Norwegian Centre for E-health Research, University Hospital of North Norway, Troms $\emptyset$, Norway

${ }^{3}$ Centre for Quality Improvement and Development, University Hospital of North Norway, Troms $\varnothing$, Norway

${ }^{4}$ Department of Community Medicine, The University of Troms $\varnothing$ - The Arctic University of Norway, Troms $\varnothing$, Norway

${ }^{5}$ Centre for Health Economics, Monash University, Melbourne, Victoria, Australia
}

Corresponding Author:

Astrid Buvik, MD

Department of Orthopaedic Surgery

University Hospital of North Norway

PO Box 4,

Tromsø, 9038

Norway

Phone: 4795255148

Email: Astrid.buvik@unn.no

\section{Abstract}

Background: Telemedicine consultations using real-time videoconferencing has the potential to improve access and quality of care, avoid patient travels, and reduce health care costs.

Objective: The aim of this study was to examine the cost-effectiveness of an orthopedic videoconferencing service between the University Hospital of North Norway and a regional medical center in a remote community located $148 \mathrm{~km}$ away.

Methods: An economic evaluation based on a randomized controlled trial of 389 patients (559 consultations) referred to the hospital for an orthopedic outpatient consultation was conducted. The intervention group (199 patients) was randomized to receive video-assisted remote orthopedic consultations (302 consultations), while the control group (190 patients) received standard care in outpatient consultation at the hospital (257 consultations). A societal perspective was adopted for calculating costs. Health outcomes were measured as quality-adjusted life years (QALYs) gained. Resource use and health outcomes were collected alongside the trial at baseline and at 12 months follow-up using questionnaires, patient charts, and consultation records. These were valued using externally collected data on unit costs and QALY weights. An extended sensitivity analysis was conducted to address the robustness of the results.

Results: This study showed that using videoconferencing for orthopedic consultations in the remote clinic costs less than standard outpatient consultations at the specialist hospital, as long as the total number of patient consultations exceeds 151 per year. For a total workload of 300 consultations per year, the annual cost savings amounted to $€ 18,616$. If costs were calculated from a health sector perspective, rather than a societal perspective, the number of consultations needed to break even was 183 .

Conclusions: This study showed that providing video-assisted orthopedic consultations to a remote clinic in Northern Norway, rather than having patients travel to the specialist hospital for consultations, is cost-effective from both a societal and health sector perspective. This conclusion holds as long as the activity exceeds 151 and 183 patient consultations per year, respectively.

Trial Registration: ClinicalTrials.gov NCT00616837; https://clinicaltrials.gov/ct2/show/NCT00616837 (Archived by WebCite at http://www.webcitation.org/762dZPoKX)

(J Med Internet Res 2019;21(2):e11330) doi: 10.2196/11330

\section{KEYWORDS}

telemedicine; orthopedics; videoconferencing; remote consultation; outpatients; randomized controlled trial; economic evaluation; cost-effectiveness analysis; QALY 


\section{Introduction}

Similar to many other countries' publicly funded national health services, a key principle in Norway is that people should have equal access for equal need irrespective of their income or region of residence [1,2]. Thus, patients' travel expenditures on public transportation are reimbursed, except a small user fee. In 2015, total reimbursement of patients' travel expenditures accounted for $2.4 \%$ of the total budget for the specialist health services [3]. In particular, patients in the northern and western part of Norway have to travel long and often burdensome journeys to receive specialist care.

Musculoskeletal injuries are the most common causes of disability and chronic pain. Surgery for orthopedic conditions is witnessing some of the greatest growth rates in developed nations across the world [4]. Decentralizing orthopedic outpatient consultations is of special interest when a large number of patients live in remote areas, many of whom are not able to use public transport, or they need assistance by accompanying persons.

Decentralized services using outreach clinics or modern information and communication technologies have the potential to improve access, avoid patient travels, and reduce health sector costs. One such technology is telemedicine consultations using real-time videoconferencing. Today, the use of telemedicine to facilitate treatment and care over a distance has been investigated in almost all clinical specialties [5-7]. Several studies have demonstrated the feasibility of using telemedicine to provide orthopedic consultations to patients living in remote areas [8-11]. Teleorthopedics involve the delivery of specialist services across a distance, usually between an orthopedic surgeon and a patient [12]. It has been reported that teleorthopedics in an outpatient setting is safe and without serious adverse events [13], and that it has increased patient satisfaction $[14,15]$, reduced travels and saved time for the patients [16,17], and reduced costs [18]. Teleorthopedics can also improve the effectiveness of rehabilitation after orthopedic surgery [4]. A study of pediatric orthopedic patients found that even greater benefit can be obtained from telemedicine consultation for patients with a disability where the cost and inconvenience of patient transport are considerably increased [19]. Videoconferencing has also successfully been used for distance training and educational purposes in the field of orthopedics [20,21]. Despite positive reporting of telemedicine studies, the uptake in clinical practice remains low [5,12,22,23].

There exist few randomized controlled trials (RCTs) evaluating telemedicine used in orthopedic outpatient clinics [24], and even fewer that have analyzed if teleorthopedic services are cost-effective compared with traditional outpatient consultations. The main arguments for introducing telemedicine services have been to reduce costs, improve efficiency, and increase quality of and access to health care services [5,25]. Hence, there is a need to determine the extent to which teleorthopedics proves to be cost-effective. Economic evaluation provides information about the costs and benefits of the alternatives under consideration [26]. Health care costs represent the value of resources used, such as staff, equipment, and consumables. Resources outside the health system can also be included such as the patients' travel time and costs. Benefits refer to the value of changes in health outcomes. These changes can be negative and worsen health or positive and improve health [25].

In this study, we report the results from an economic evaluation. The primary objective of this study was to examine the cost-effectiveness of the telemedicine service, compared with standard in-person consultations at the hospital from a societal perspective. The secondary objective was to assess the robustness of the results by conducting sensitivity analysis. The costs included were health care costs, patient costs, and time costs measured as production loss. Health outcomes were measured as quality-adjusted life years (QALYs) gained.

\section{Methods}

\section{Study Design and Recruitment}

The economic study was based on a prospective RCT. This trial was conducted to assess if remote consultations using videoconferencing in orthopedic consultation was as safe and effective as in usual in-person care. Patients were recruited from the 4 northernmost municipalities in Troms County (Figure 1). All participants had been referred to or had scheduled a visit at the orthopedic outpatient clinic at the University Hospital of North Norway (UNN) and found to be suitable for a video-consultation. Patients were excluded if they were in need of any of the following: an advanced physical examination, a computed tomography scan, an ultrasound, an interpreter, seeing a specific surgeon, or if unable to give informed consent. Of the 402 patients who were randomized into 2 groups, 13 withdrew from the study or did not meet for the consultations. This left 389 patients in the study. Patients randomized to the intervention group received remote orthopedic video-consultations at the Regional Medical Center (RMC) $(n=199)$. Patients randomized to the control group received standard outpatient consultations at the hospital $(n=190)$. Informed consent was obtained from all the participants. The study was approved by the Regional Committee for Medical and Health Research Ethics.

\section{Equipment and Training}

The remote consultations were performed through real-time videoconferencing. Both the remote center and the hospital used the Cisco TelePresence System and the Norwegian Health Network for secure data transmission (Screen: ViewSonic, Modl nr VS10946-Ie; at the remote center: Tandberg 990MXP; at the hospital: Tandberg 1500MXP). The orthopedic surgeons had some initial training and technical assistance in the beginning of the trial. Registered nurses were operating the service at the remote center. Before the trial, 2 nurses from the remote clinic received intensive training both to operate the technical equipment and to assist in treating the patients locally. They attended casting courses and were trained in clinical examination techniques. 
Figure 1. Norway and the area where the study patients were recruited and location of the University Hospital of North Norway and Regional Medical Center (inserted).

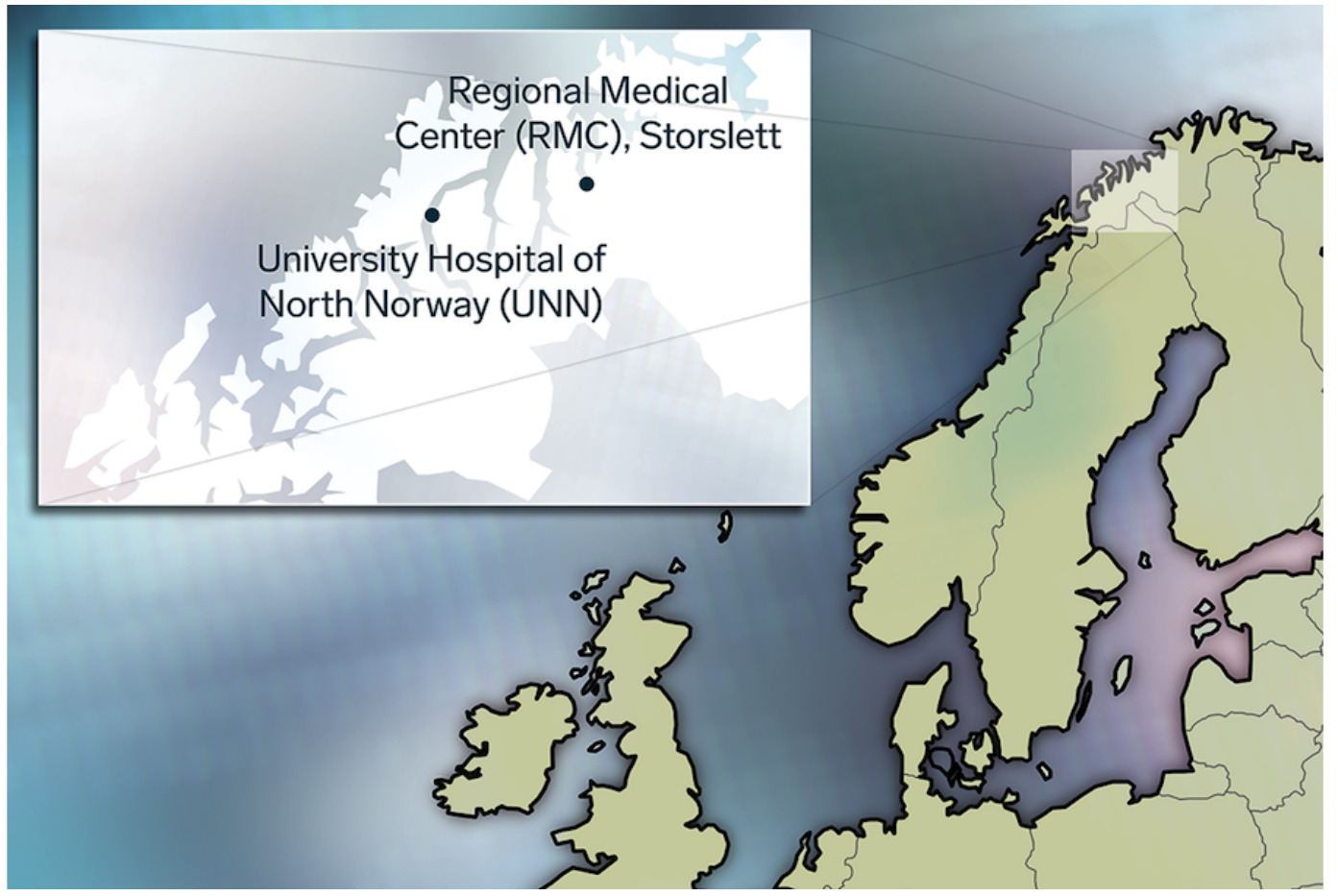

\section{The Remote Consultation}

The patients were scheduled for an appointment at the local center by the surgeon at the hospital. The orthopedic surgeons (3 consultants and 2 experienced registrars) were randomly selected to conduct the video-consultations if they were available at the specific time. The surgeon made the videoconference call to the remote center.

The patients showed up and were welcomed by one of the trained nurses who set up the videoconferencing at the remote site. The nurses assisted during the consultation and performed physical tasks, for example, changed a cast or removed stitches. No physician was present during the video consultations at the remote site. An existing digital X-ray lab served by a local radiographer was available at the remote clinic. Digital X-rays were, if needed, available and shown to the patients at the time of the consultation.

\section{Usual Care}

In the control group, patients received standard consultations at the hospital outpatient clinic. In $32 \%$ of the standard consultations, the orthopedic surgeons needed assistance from a nurse [13].

In both the standard and the video consultation alternatives, the usual mandatory registration and documentation in patients' medical records were carried out by the orthopedic surgeon. This involves the conclusion of the consultation, agreement between surgeon and patient regarding any follow-up appointments, prescriptions, referrals for operation, further investigations, physiotherapy, and an application for orthopedic aid if needed. The average number of consultations per patient was 1.5 (range 1-6). For more details of the trial method, see Buvik et al [13].

\section{Economic Evaluation}

The economic evaluation consisted of trial-based analyses following the guidelines for health economic evaluation [27,28]. The cost and effectiveness data used in the economic study were based on actual investments, personnel costs, patient travels, and health outcomes collected during the trial described above. A societal perspective was adopted for calculating costs including health care costs, private costs, and production loss. Effectiveness was measured in terms of QALYs gained.

Data on costs and QALYs gained were collected alongside the trial at baseline and at 12 months follow-up using questionnaires, patient charts, and consultation records. These were valued using externally collected data on unit costs and utilities. To increase generalizability and make the cost-effectiveness result useful for decision making, the resources used in the trial were valued using equipment prices, unit costs, travel fares, and salaries from 2017/2018. An extended sensitivity analysis was conducted to address the robustness of the results.

\section{Costs}

Three types of costs were included: (1) costs associated with implementing and running the telemedicine service in clinical practice, (2) travel costs, and (3) production losses.

\section{Costs Associated With Implementing and Running the Service}

The implementation costs included the costs related to the investment in videoconferencing equipment (codec, screen, and camera) at the remote center and the hospital, and an extra computer and printer at the remote center. The remote center already had a broadband connection for other purposes. The computer at the remote center provided the nurse access to the patients' hospital records, and the printer was used to give patients a paper copy of the records on request. In addition, 
costs related to running the service at the remote center were estimated. This included a registered nurse in a $20 \%$ position. Other costs associated with setting up the service included initial training sessions and travel costs related to these activities, line rent, and rent associated with the extra space needed at the local center. No extra technical support was needed as they used existing resources at the hospital. The costs estimated were only those that differed between telemedicine and hospital consultations, that is, the incremental costs. The time costs for the orthopedic surgeons were the same for both consultation forms [13]. The consumables, X-ray, and administrative costs were assumed to be similar for both groups. The cost of the nursing assistance during the standard consultations was also included. Equipment prices and line rent for both the remote clinic and the hospital were collected from the purchasing department at the hospital. A one-time equipment cost can be spread over the expected lifetime of the equipment by annuitizing the cost using a discount factor. The investment costs including equipment, installation, and training were annuitized into an equivalent annual cost assuming a $3 \%$ discount rate and a 5-year lifespan for the equipment. The costs of the extra space and other facilities at the local center were collected from financial and administrative records at the hospital. Official salary for nurses was used to estimate the costs of the extra nurse position. The costs are presented as total annual costs and costs per patient consultation (unit costs).

\section{Travel Costs}

Travel costs were collected directly from the patients during the trial. Data on traveling time, distance, and mode of transport to the consultation were collected using a questionnaire that was handed to the patient directly after each consultation. Main occupation, if they were on sick leave, and the need of overnight stay were also included. Additionally, Google map was used to estimate the travel distance from the patients' home to the consultation site either at the remote center or at the hospital (shortest and fastest). The orthopedic surgeon decided if the patient needed a companion or extra transportation on health-related grounds, reported the patients' main occupation, and if they needed sick leave. The travel costs were calculated using regulations and official travel fare rates by the Norwegian Patient Travel Agency in 2018 [29].

\section{Production Losses}

Production losses were estimated for patients in full- or part-time employment who had to take time off from work to attend the orthopedic consultations. Part-time employment was set to $50 \%$. Time costs for the patients who were unemployed or on sick leave benefits were not included. If the information about working status was missing from the self-reported questionnaires, the orthopedic surgeons' registration forms were used. Official Norwegian average wages were used to value absence from work to estimate the production losses.
Only 3 of the 199 patients who were offered a video consultation at the remote center had a new consultation at the hospital, because of their need for a face-to-face consultation to carry out examination that is not possible over the video link. The cost of these second consultations was also included in the analysis. Based on the resources available at the hospital and the experiences from the trial, we assumed that for 300 patient consultations annually, 5 would need a second consultation.

\section{Quality-Adjusted Life Years Gained}

Health outcomes were measured in QALYs gained, a composite measure incorporating both quantity and quality-of-life impacts of treatment [26]. As a patient-reported outcome measure, we applied the EQ-5D which is the most widely used generic preference-based instrument for valuing QALYs [30]. EQ-5D questionnaires were collected at baseline and at 12 months follow-up. The questionnaires were handed to the patients immediately after the first consultation and sent by mail 12 months after the last consultation during the trial. The scoring algorithm estimated for a sample of the general population in United Kingdom was used to calculate utility values from the utility scored in the EQ-5D instrument (the EuroQol health states) [31]. Utility values were calculated only if all 5 of the EQ-5D dimensions were answered. Finally, QALYs were then calculated by multiplying the change in utility value with the duration of the health state (1 year) [26].

\section{Statistical Analysis}

Results are presented as means (SDs) or numbers (percentages). Differences between the groups were analyzed using 2 sample $t$ tests, chi-square tests, or generalized estimating equations (GEEs). GEEs were used with an exchangeable covariance structure to control for dependence between 2 or more repeated consultations for some participants. All statistical analyses were performed using STATA version 14.0 (StataCorp LP Texas, USA).

\section{Sensitivity Analysis}

One-way sensitivity analyses were conducted to assess the robustness of the results. Parameters have been varied one at a time to assess the effect on the cost-effectiveness and to determine breakeven values. We recalculated the cost analysis in 3 separate scenarios: one included a less costly Skype for Business solution, the second assumed a shorter distance to the main hospital, and a third scenario includes the expenditure to the hospital excluding patients' own travel expenditures and production losses. The number of consultations needed to break even was calculated for all scenarios.

\section{Results}

Table 1 provides characteristics of the participants at baseline. 
Table 1. Descriptive baseline characteristics from first consultation according to location.

\begin{tabular}{|c|c|c|}
\hline Baseline characteristics of the participants (n) & $\mathrm{UNN}^{\mathrm{a}}$ standard consultation $(\mathrm{n}=190)$ & $\mathrm{RMC}^{\mathrm{b}}$ telemedicine consultation $(\mathrm{n}=199)$ \\
\hline Males, n (\%) & $75(39.5)$ & $82(41.2)$ \\
\hline Age (years), mean (SD) & $46.7(24.9)$ & $48.8(24.0)$ \\
\hline \multicolumn{3}{|l|}{ Age group (years), n (\%) } \\
\hline $1-15$ & $42(22.1)$ & $29(14.6)$ \\
\hline $16-66$ & $94(49.5)$ & $117(58.8)$ \\
\hline $67-90$ & $54(28.4)$ & $53(26.6)$ \\
\hline \multicolumn{3}{|l|}{ Patient residential municipality, n (\%) } \\
\hline Kvænangen & $25(13.2)$ & $26(13.0)$ \\
\hline Nordreisa & $82(43.2)$ & $90(45.2)$ \\
\hline Skjervøy & $47(24.7)$ & $45(22.6)$ \\
\hline Kåfjord & $36(18.9)$ & $38(19.1)$ \\
\hline \multicolumn{3}{|l|}{ Cause of consultation, $\mathbf{n}(\%)$} \\
\hline New referral & $69(36.3)$ & $81(40.7)$ \\
\hline Control after elective surgery & $25(13.2)$ & $22(11.1)$ \\
\hline Control after trauma, surgery & $33(17.4)$ & $35(17.6)$ \\
\hline Control after trauma, no surgery & $55(28.9)$ & $50(25.1)$ \\
\hline Chronic disease & $8(4.2)$ & $11(5.5)$ \\
\hline \multicolumn{3}{|l|}{ Employment status $(n=177+190)^{c}, n(\%)$} \\
\hline Full-time worker & $45(25.4)$ & $56(29.5)$ \\
\hline Part-time worker & $23(13.0)$ & $20(10.5)$ \\
\hline Homemaker & $12(6.8)$ & $19(10.0)$ \\
\hline Unemployed & $2(1.1)$ & $2(1.1)$ \\
\hline Retired or disability benefit & $55(31.1)$ & $61(32.1)$ \\
\hline Student or pupil & $40(22.6)$ & $32(16.8)$ \\
\hline EQ-5D-3L index $(n=165+178)^{\mathrm{c}}$, mean $(\mathrm{SD})$ & $0.70(0.25)$ & $0.68(0.26)$ \\
\hline EQ VAS $1-100(n=140+150)^{\mathrm{c}}$, mean $(\mathrm{SD})$ & $75(18)$ & $73(19)$ \\
\hline
\end{tabular}

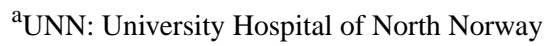

${ }^{\mathrm{b}} \mathrm{RMC}$ : Regional Medical Center.

${ }^{\mathrm{c}}$ Number of item responses in UNN and RMC, respectively.

\section{Costs}

\section{Costs Associated With Implementing and Running the}

\section{Service}

The costs of setting up the teleorthopedic service are presented in Table 2. Total costs of investing in standard videoconferencing units at both sites were $€ 16,511$ ( 1 Euro $=9.60$ Norwegian krone, April 10, 2018). The total annual costs including annuitized investment costs (equipment and initial training), line rent, extra personnel costs, and rent for extra office space at the regional center were $€ 20,684$. The largest cost component is the extra nursing costs at the local health center. Nearly, two-thirds of the total annual cost of the teleorthopedic service are extra personnel costs. If a less costly Skype for Business alternative had been used, the annual costs would have been reduced to $€ 17,535$ (see Table 2 for more details). 
Table 2. The costs of setting up a video-assisted outpatient clinic (in Euro).

\begin{tabular}{|c|c|c|c|c|}
\hline Cost elements & $\mathrm{UNN}^{\mathrm{a}}$ standard consultation & $\mathrm{RMC}^{\mathrm{b}}$ telemedicine consultation & Total (Euro) $)^{\mathrm{c}}$ & Annual cost \\
\hline \multicolumn{5}{|l|}{ Alternative $\mathbf{A}^{\mathrm{d}}$} \\
\hline Videoconferencing equipment & 5104 & 6250 & 11,354 & - \\
\hline Personal computer (PC) & - & 463 & 463 & - \\
\hline Screen & - & 156 & 156 & - \\
\hline Printer & - & 114 & 114 & - \\
\hline Initial training of nurse and physician & - & - & 4424 & - \\
\hline Total investment A & & & 16,511 & $3605^{\mathrm{e}}$ \\
\hline \multicolumn{5}{|l|}{ Additional costs alternative A } \\
\hline Line rental, Norwegian Health Net & - & $104^{\mathrm{f}}$ & - & 1250 \\
\hline Sum alternative $\mathrm{A}$ & & & & 4855 \\
\hline \multicolumn{5}{|l|}{ Alternative $\mathbf{B}^{\mathrm{g}}$} \\
\hline Camera & 96 & 937 & 1033 & - \\
\hline Screen & - & $833 \times 2$ & 1666 & - \\
\hline Microphone & 111 & - & 111 & - \\
\hline $\mathrm{PC}$ & - & 463 & 463 & - \\
\hline Printer & - & 114 & 114 & - \\
\hline Initial training of nurse and physician & - & - & 4424 & - \\
\hline Total investment B & & & 7811 & $1706^{\mathrm{e}}$ \\
\hline \multicolumn{5}{|l|}{ Additional costs alternative $A$ and $B$} \\
\hline Technical support ${ }^{\mathrm{h}}$ & - & - & - & - \\
\hline Rent for local RMC & - & - & - & 3542 \\
\hline Nurse at $\mathrm{RMC}^{\mathrm{i}}$ & - & - & - & 12,083 \\
\hline $\begin{array}{l}\text { In need of a second consultation at the } \\
\text { hospital }^{j}\end{array}$ & & & & 204 \\
\hline Total additional costs & & & & 15,829 \\
\hline Total annual cost alternative A & & & & 20,684 \\
\hline Total annual cost alternative $B$ & & & & 17,535 \\
\hline
\end{tabular}

${ }^{\mathrm{a}} \mathrm{RMC}$ : Regional Medical Center, remote location.

${ }^{\mathrm{b}} \mathrm{UNN}$ : University Hospital of North Norway, standard consultation.

${ }^{c} 1$ Euro=9.60 Norwegian krone, exchange rate from the Norwegian Bank on April 10, 2018.

${ }^{\mathrm{d}}$ Alternative A: Videoconferencing units: UNN—Cisco TelePresence System EX90; RMC—Cisco TelePresence MX200 G2 (prices obtained from the purchasing department at the hospital).

${ }^{\mathrm{e}}$ Annual cost has been calculated using a $3 \%$ discount factor and a 5-year lifetime of the equipment.

${ }^{f}$ Per month.

${ }^{\mathrm{g}}$ Alternative B: Skype for Business: UNN—Camera Logitech: Webcam C930e—net camera; Tablemicrofon: Jabra SPEAK 510+MS (already installed $1 \mathrm{PC}$ and 2 screens for standard consultations); RMC -2 screens Philips Signage Solutions Q-Line BDL5535QL+camera/microphone Logitech GROUP+PC (prices obtained from the purchasing department at the hospital).

${ }^{\mathrm{h}}$ Technical support—no extra costs included as this support has been covered by existing support at the hospital.

${ }_{2} 20 \%$ part time, including social costs.

${ }^{\mathrm{j}}$ Three patients needed a second consultation at UNN because of an unsatisfactory consultation at the RMC during the trial (out of 199 patients) [13]. Since we have assumed 300 patients a year in the teleconsultation alternative, costs of a second consultation have been included for 5 patients per year. 


\section{Travel Costs}

Table 3 shows details on patients' modes of transport. Most patients in the remote group traveled by private car. The chosen mode of transportation reflects the lack of available public transportation in the area. In the group of patients traveling to the hospital, $26 \%$ needed extra transportation facilities because of their health condition. This number was $30 \%$ for the patients in the telemedicine group $(P=.31)$. In addition, the need for travel companions was the same in both groups $30 \%$ in the hospital consultation group and $27 \%$ in the telemedicine group; $P=.45)$. The time spent on traveling was 6 times higher for patients traveling to the hospital. Patients in the telemedicine group saved an average 7 hours and 40 minutes on traveling (see Table 4 for more details). The average travel cost per patient is $€ 148.65$ for the standard consultations at the hospital, as compared with $€ 40.73$ for the video consultations, including user fees for the patients ( $€ 31.04$; see Multimedia Appendix 1).

Table 3. Patient transport mode to each consultation per allocation. Of the 389 patients participating in this study, some attended more than 1 consultation; consequently, the total number of consultations in this study was 559 (257 at UNN and 302 at RMC).

\begin{tabular}{|c|c|c|c|c|}
\hline Transport mode & $\mathrm{UNN}^{\mathrm{a}}, \mathrm{n}(\%)$ & $\mathrm{RMC}^{\mathrm{b}}, \mathrm{n}(\%)$ & $P$ value ${ }^{\mathrm{c}}$ & $P$ value, $\mathrm{GEE}^{\mathrm{d}}$ \\
\hline $\operatorname{Taxi}^{\mathrm{e}}$ & $55(21.4)$ & $60(19.9)$ & .57 & .77 \\
\hline Taxi, as main transport & $47(18.3)$ & $60(19.9)$ & .71 & .56 \\
\hline Airplane & $3(1.1)$ & 0 & $N / A^{f}$ & N/A \\
\hline $\mathrm{Bus}^{\mathrm{g}}$ & $72(28.0)$ & $6(2.0)$ & $<.001$ & $<.001$ \\
\hline Bus, as main transport & $66(25.7)$ & $6(2.0)$ & $<.001$ & $<.001$ \\
\hline Private car ${ }^{\mathrm{h}}$ & $106(41.2)$ & $211(69.9)$ & $<.001$ & $<.001$ \\
\hline Private car, as main transport & $98(38.1)$ & $209(69.2)$ & $<.001$ & $<.001$ \\
\hline Express boat & $28(10.9)$ & 0 & $<.001$ & N/A \\
\hline Ferry ${ }^{\mathrm{i}}$ & $19(7.4)$ & $7(2.3)$ & .004 & .01 \\
\hline Other $^{j}$ & 0 & $15(5.0)$ & $<.001$ & N/A \\
\hline Not reported or Missing & $16(6.2)$ & $13(4.3)$ & .31 & N/A \\
\hline
\end{tabular}

${ }^{a}$ UNN: University Hospital, standard consultation.

${ }^{\mathrm{b}} \mathrm{RMC}$ : Regional Medical Center, remote location.

${ }^{\mathrm{c}}$ Test for equality between UNN and RMC using chi-square test.

${ }^{\mathrm{d}}$ Test for equality between UNN and RMC using generalized estimating equations (GEEs) with a logit link function and a binary response, transport (yes or no).

${ }^{\mathrm{e}}$ Including taxi as shuttle to other transport (bus, express boat, or airplane).

${ }_{\mathrm{f}} \mathrm{N} / \mathrm{A}$ : not applicable, few or no observations.

${ }^{\mathrm{g}}$ Including bus as shuttle to other transport (airplane or express boat).

${ }^{\mathrm{h}}$ Including private car as shuttle to other transport (bus, express boat, airplane, or taxi).

${ }^{\mathrm{i}}$ Always in combination with other transport (bus, private car, express boat, or taxi).

${ }^{\mathrm{j}}$ Walking, bicycle, or working car. 
Table 4. Patients' travel details and working status.

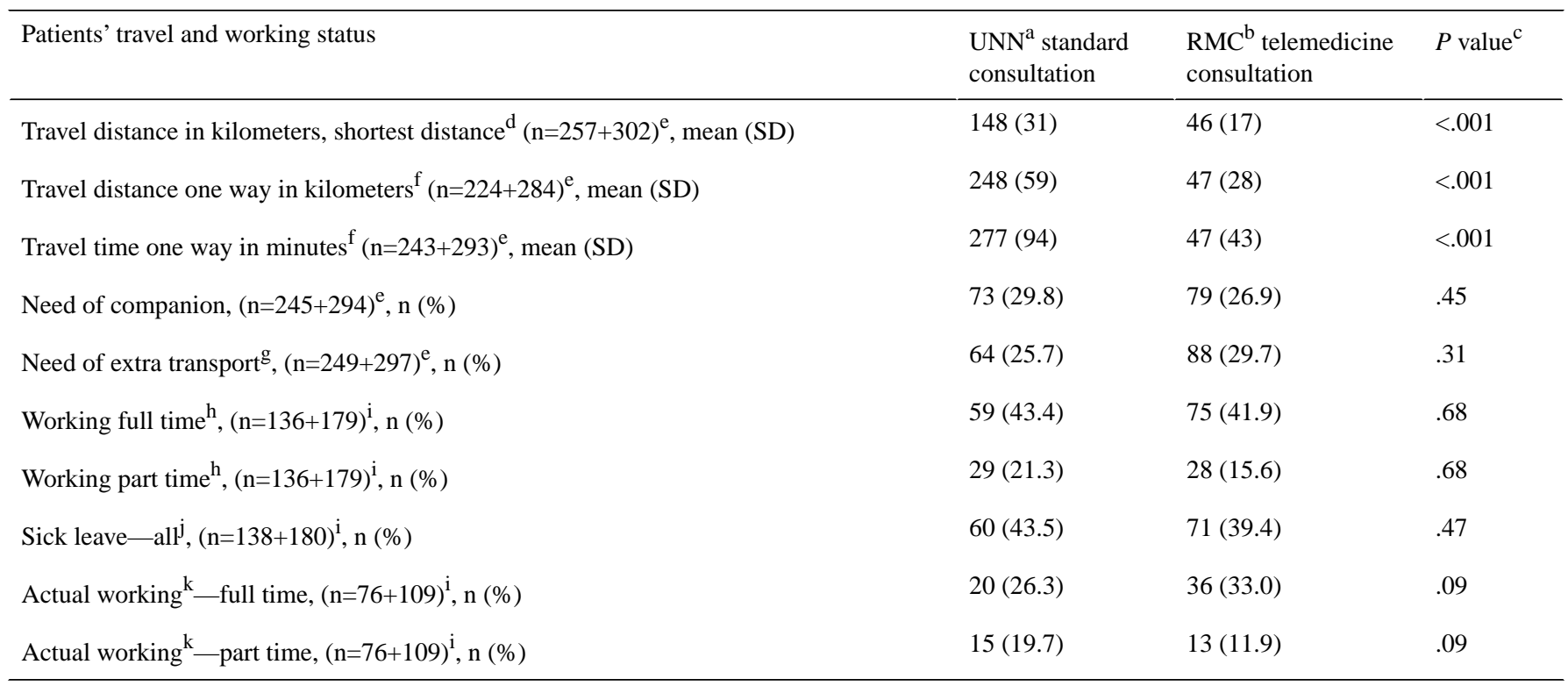

${ }^{\mathrm{a}}$ UNN: University Hospital North Norway, standard consultation.

${ }^{\mathrm{b}} \mathrm{RMC}$ : Regional Medical Center, remote location.

${ }^{\mathrm{c}}$ Test for equality between UNN and RMC using $t$ test or chi-square test as appropriate.

${ }^{\mathrm{d}}$ Calculated road between allocation and municipality center using Google Map, one way. The travel distance for the patient in the municipality, where the RMC is located, is replaced with the mean value of the municipalities' patients reported travel distance.

${ }^{\mathrm{e}}$ Number of item responses in UNN and RMC, respectively.

${ }^{\mathrm{f}}$ Patients reported distance or time used to travel to the consultation.

${ }^{\mathrm{g}}$ Need extra transport, as patient was not able to use public transport.

${ }^{\mathrm{h}}$ Patient reported (age between 15 and 67 years), missing value adjusted by doctors reported value.

${ }^{\mathrm{i}}$ Number of item responses in UNN and RMC, respectively, age between 15 and 67 years.

$\mathrm{j}_{\text {Including unemployed and homemakers. }}$

${ }^{\mathrm{k}}$ Working_-patient not with sick leave.

\section{Production Losses}

Production losses for patients who had to be away from work to attend the consultations, the total average costs of the patient transfer amounted to $€ 182.50$ per patient for the standard consultations and $€ 51.77$ for the teleconsultations. The calculation of travel and time costs for the patients is presented in detail in Multimedia Appendix 1.

\section{Quality-Adjusted Life Years Gained}

The average QALYs gained per patient in the telemedicine group was .09 which was not significantly different to the .05 gain in the standard consultation group, $P=.29$.

\section{Cost and Effectiveness}

Table 5 presents the costs and effects in each of the 2 alternatives. Among patients in the intervention group, 3 needed a second face-to-face consultation that was not possible to carry out over the video link. The cost of these second consultations was also included in the analysis (Table 5). In total, the telemedicine service costs $€ 65$ less per patient than standard consultations at the hospital. Thus, the remote teleorthopedic service is less costly and produced no difference in health outcome, that is, the teleorthopedic service as described in this study is cost-effective. The number of patient consultations needed for telemedicine and standard consultation to be equally costly (breakeven) is 151 patients per year (see Figure 2). 
Table 5. Costs and effectiveness for standard and remote consultations ( 1 Euro $=9.60$ Norwegian krone, exchange rate from the Norwegian Bank on April 10, 2018).

\begin{tabular}{|c|c|c|c|}
\hline Costs and effectiveness & $\mathrm{UNN}^{\mathrm{a}}$ standard consultation & $\mathrm{RMC}^{\mathrm{b}}$ telemedicine consultation & Difference \\
\hline \multicolumn{4}{|l|}{ Consultation costs $^{\mathbf{c}}$ (Euro) } \\
\hline Investment cost videoconferencing ${ }^{\mathrm{d}}$ & 0 & 3605 & 3605 \\
\hline Line rent & 0 & 1250 & 1250 \\
\hline Room rent & 0 & 3542 & 3542 \\
\hline Personnel costs (nurse) ${ }^{\mathrm{e}}$ & 906 & 12,083 & 11,177 \\
\hline In need of a second consultation at the hospital $\mathrm{f}^{\mathrm{f}}$ & 0 & 204 & 204 \\
\hline Total annual costs & 906 & 20,684 & 19,778 \\
\hline Cost per consultation ${ }^{\mathrm{g}}$ & 3 & 69 & 66 \\
\hline \multicolumn{4}{|l|}{ Time and travel costs (Euro) } \\
\hline Travel costs & 149 & 41 & 108 \\
\hline Time costs ${ }^{\mathrm{h}}$ & 34 & 11 & 27 \\
\hline Total time and travel costs per consultation & 183 & 52 & 131 \\
\hline Total costs per patient consultation & 186 & 121 & 65 \\
\hline Effectiveness (QALYs ${ }^{\mathrm{i}}$ gained) & .05 & .09 & $.04^{\mathrm{j}}$ \\
\hline
\end{tabular}

${ }^{\mathrm{a} U N N}$ : University Hospital of North Norway.

${ }^{b}$ RMC: Regional Medical Center.

${ }^{\mathrm{c}}$ Consultations cost which are different between the 2 groups.

${ }^{\mathrm{d}}$ Total investment costs have been annuitized using 3\% discount factor and a 5-year lifetime.

${ }^{\mathrm{e}}$ The extra personnel costs at the remote location included a nurse in $20 \%$ position. At the standard consultation, a nurse was present in $32 \%$ of the consultations, corresponding to 25 hours by 300 consultations a year.

${ }^{\mathrm{f}}$ Three patients needed a second consultation at UNN because of an unsatisfactory consultation at the RMC during the trial (out of 199 patients) [13]. Since we have assumed 300 patients a year in the teleconsultation alternative, costs of a $2^{\text {nd }}$ consultation have been included for 5 patients per year.

${ }^{\mathrm{g}}$ The annual load for this service is estimated to be 300 telemedicine consultations per year.

${ }^{\mathrm{h}}$ Production loss because of absence from work to receive orthopedic consultation.

${ }^{\mathrm{i}}$ QALYs: quality-adjusted life years.

${ }^{\mathrm{j}}$ The difference in QALYs gained was not significant $(P=.29) t$ test. 
Figure 2. Total annual costs of the teleorthopedic service including the Skype for Business alternative.

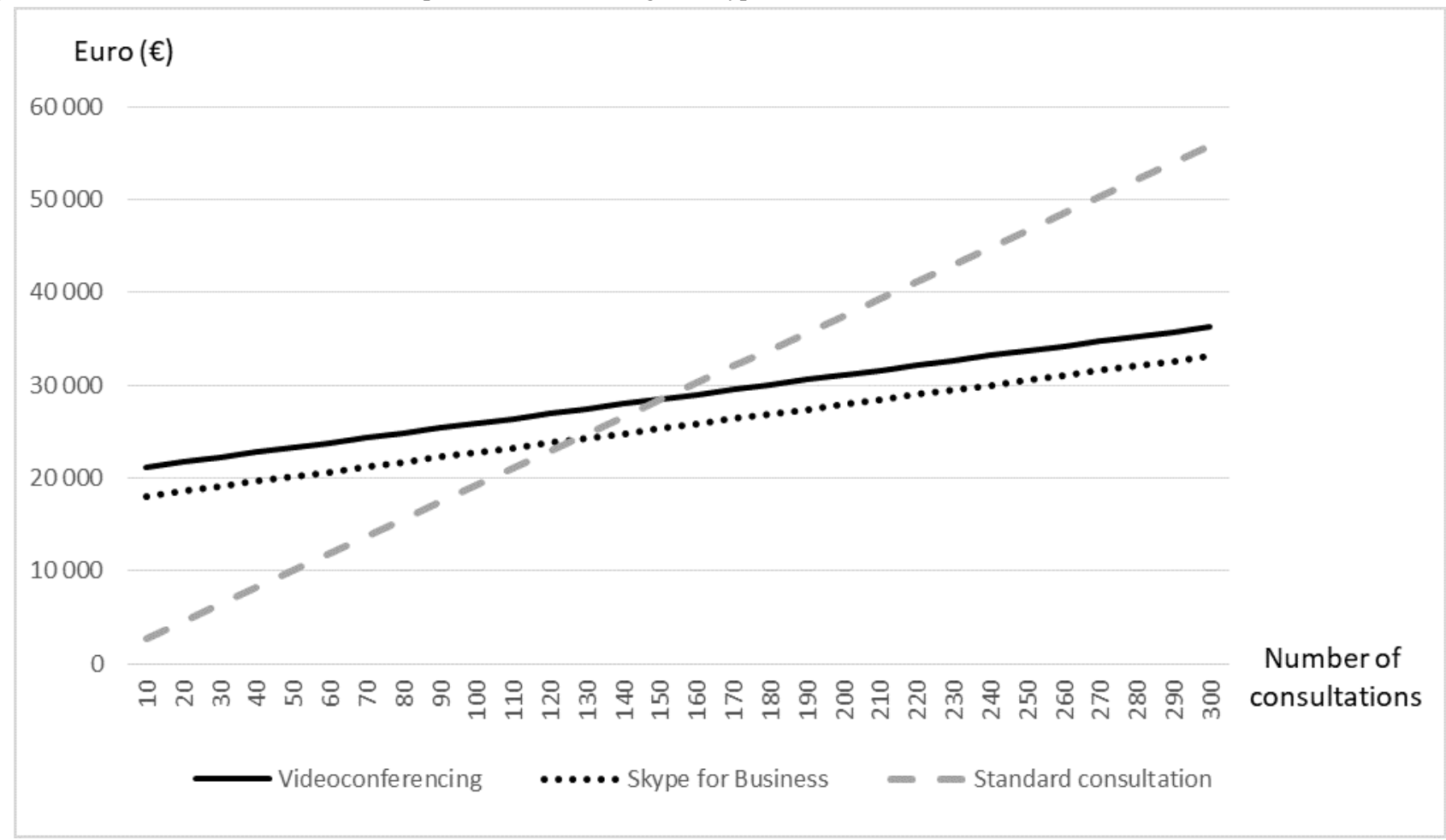

\section{Sensitivity Analysis}

The different scenarios in the sensitivity analyses are illustrated in Figures 2 and 3. The main case alternative described above is represented by the solid black curve (videoconferencing) and the gray dotted line (standard consultation at the hospital). The first scenario included a less costly Skype for Business alternative. The total annual cost of this alternative was $€ 17,535$, and the number of patient consultations needed to break even was 127 per year (dotted black line). The second scenario, assuming a shorter distance $(90 \mathrm{~km})$ between the remote clinic and the hospital, needed 314 patient consultations to breakeven using videoconferencing units (not shown). The third scenario included only expenditures to the hospital excluding production losses and patients' own travel expenditures. This made telemedicine cost-effective for an activity of at least 183 patient consultations a year (not shown).

Figure 3. Cost per patient for base case and the Skype for Business alternative.

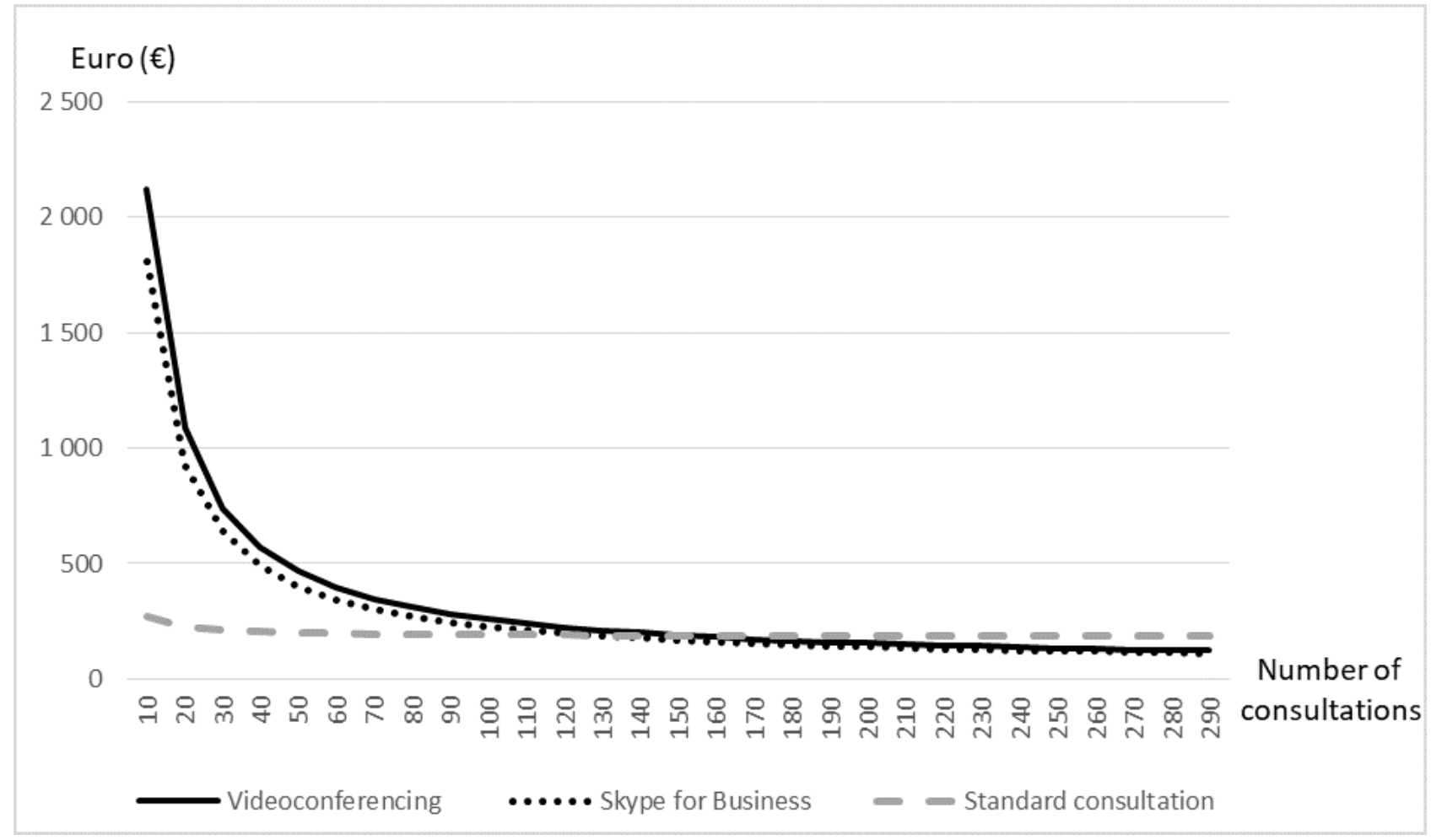




\section{Discussion}

\section{Principal Findings}

The results of this study showed that using videoconferencing to offer orthopedic consultations to patients at the remote clinic costs less than standard outpatient consultations at the specialist hospital, as long as the activity exceeds a minimum of 151 patient consultations per year. For a total workload of 300 patients per year, the annual cost savings amounted to $€ 19,500$. With a health care sector cost perspective, the number of patient consultations needed to break even was 183 , and the total annual savings amounted to $€ 12,600$. Thus, teleorthopedics is cost-effective from both a societal and health care provider perspective. A shorter distance to the hospital was the only scenario that altered the conclusion. Reducing the travel distance by $50 \mathrm{~km}$ made the standard consultation more cost effective for up to 314 patients per year.

Assuming a less expensive Skype for Business alternative reduced the cost of telemedicine with $€ 3149$ annually, this alternative became cost-effective when including more than 127 patient consultations per year. The reduction in costs by investing in a cheaper videoconferencing solution was relatively modest. One of the reasons is that the equipment cost was less compared with the other cost components such as the extra personnel needed at the remote site. The quality of the videoconferencing might also be reduced using Skype for Business, and more patients would need a second consultation at the hospital making the cost advantage even less. We have not evaluated if a Skype for Business alternative will reduce the quality in picture and/or sound transmission. Other options to reduce the equipment costs are to increase utilization and share the videoconferencing units with other specialties/other use (eg, teaching or meetings) [32]. These possibilities should be considered before setting up video consultations in a specific field.

In most of the published literature, a physician (eg, a general practitioner [GP], a general surgeon, or a resident) has been present at the remote site together with the patient $[8,10,11,33,34]$. Some studies reported that a nurse at the remote site and a specialist at the hospital could provide satisfactory remote consultations in emergency medicine [35-37]. Wallace et al recommend to include a nurse to host the teleconsultations in place of the GP to reduce the cost of telemedicine [38]. In this study, a nurse was hosting the teleconsultations at the remote site. To our knowledge, no other studies have reported a similar setting when studying the use of teleorthopedics for newly referred patients or follow-up consultations. However, the extra personnel costs still consist of nearly two-thirds of the total annual cost of the teleorthopedic service even if a nurse is hosting the teleconsultations.

Whether to include production losses measured as time off work is controversial [39]. The patients may already be off work, because they are retired or because of their health condition. Health visits of a shorter duration might not represent production losses at all. Some types of work can be postponed until the person is back or one's colleagues can take over. The time costs are important in telemedicine and eHealth, and one should find a way to include these costs [25]. In this study, production loss has only been included for those who reported that they took time off work to attend the consultation. From a societal perspective, these costs are relevant, but not from a health care provider perspective. Excluding the production loss does not change the cost-effectiveness as shown in the sensitivity analysis. Another way is to report the time (hours or days) lost or gained separately without putting a value on it [26]. Our results show that patients receiving standard consultations spent almost 8 hours more per consultation traveling than the patients in the telemedicine group.

Other studies have reported a reduction in the number of referrals to the specialist because of a learning effect and included this as part of the cost savings $[32,40]$. In this study, the nurse at the remote center reported an increase in the number of patients treated locally mostly because of their newly acquired casting skills. This was seen for patients with a stable fracture (not displaced). If this effect had been included in our analysis, the service would have reduced the need for specialist referrals and incurred additional cost savings.

A third option to prevent the patient from traveling long distances is to have the specialist travel from the hospital to the remote location. However, because of a lack of orthopedic specialists at the central hospital in this region, the opportunity costs of their travel time would be too high. However, in other institutional contexts, this might be another alternative to consider.

In this study, we demonstrated that significantly less public transport such as a bus or boat was used in the remote consultation group (Table 3 ). This can be explained by the lack of available public transport in the rural area, something that explains the frequent use of taxi and private cars. Expensive and long travels imply that fewer patients are needed to make remote consultations cost-effective.

\section{Strengths and Limitations}

The main strength of this study is that the costs and effects have been collected alongside an RCT. The estimated travel costs included in the analysis are based on the actual journeys undertaken by the participants in the trial. The time and travel cost calculation was based on actual travel distances, modes of transportation, how many in need of a companion, time spent on traveling, and the working status of each patient. Official travel fares reimbursed from the Norwegian Patient Travel Agency were used as unit costs. Some of the patients' journeys were organized by the Norwegian Patient Travel Agency (most of the taxi trips and flights). The patients had to apply for reimbursement for additional expenses.

Official travel fares reimbursed by the Norwegian Patient Travel Agency were used to calculate the travel costs. If the patients chose to travel by a more expensive alternative than the travel agency's reimbursement (eg, by plane), the patients had to pay for the difference themselves. This makes the true travel costs for the patients potentially higher than estimated in this study. It is also possible that the actual travel costs for the health care sector are lower than calculated. Some patients did not apply for travel refund, either because they forgot or simply because 
they found it too troublesome to fill out the forms. One study from Norway demonstrated that $26 \%$ of the patients and $70 \%$ of the accompaniers did not apply for a travel refund [41].

Another limitation of this study is that production loss for the persons accompanying the patients on travels was not included. The main reason for this was the lack of information about their working status, and it was considered important to avoid overestimating the benefits of the service. About $28 \%$ of the patients needed a travel companion. If these time costs were included, it would have made the teleorthopedic service even more cost-effective.

Training costs have been included as a one-time cost at the startup of the teleorthopedic service. However, training should be included as an ongoing part of the service to promote and sustain use. Training is necessary because of staff turnover, particularly at the hospital. Casting courses and training in clinical examination techniques must also be arranged if there is a change in the nursing staff locally. Telemedicine services are often sensitive to changes in key personnel [42]. Successfully sustaining telemedicine services is about integration and effective change management [43].

\section{Generalizability}

One challenge for economic evaluations of telemedicine services is generalizability. High diversity in terms of objectives, technology, application, and context might limit the generalizability of specific evaluations to other settings [44]. The local context will decide the cost parameters such as the need for investment in technology and infrastructure, prices, the costs of extra personnel, and travel and time costs. The results of an economic evaluation are of most value for decision makers in the local area where the evaluation was conducted. It is important to assess if the assumptions, cost parameters, and context can be compared between settings.

To make this study relevant outside of the current institutional setting, we have emphasized a transparent calculation of all cost and effectiveness items, based on 2 costing perspectives. The same methodology can then be generalized, however, based on local prices.

\section{Conclusions}

This study showed that providing video-assisted orthopedic consultations at a remote clinic, rather than having patients travel to a centrally located hospital for consultations is cost saving. This conclusion holds from both a societal and a health sector perspective and as long as the activity exceeds 151 and 183 patient consultations per year, respectively.

\section{Acknowledgments}

The authors would like to thank Solveig Nørgaard and Anne-Sofie Høgbakk for assisting at the remote consultation; Ann Kristin Hansen and Vegard Fossum for data collection; Kerstin Aune for assisting with the patient questionnaires; physician and staff at the orthopedic outpatient clinic and the department at UNN for recruiting patients; GP in the region for recruiting patients; the Clinical Research Centre at the UNN, Inger Sperstad, Samline Grimsgaard, Inger Sandstad; Norwegian Centre for Integrated Care and Telemedicine, UNN, Lars Rye and Jan Hugo Olsen, and all the patients who participated in this study. The study was funded by a research grant from the North Norway Regional Health Authority (HST 950-10, ID 3543).

\section{Authors' Contributions}

AB contributed to the study design, data collection, data analysis, interpretation, and writing of the manuscript. TB contributed to the study design, interpretation, data analysis, and writing of the manuscript. EB contributed to the study design, interpretation, and writing of the manuscript. AS contributed to the study design, data collection, and writing of the manuscript. TW contributed to the study design, data analysis, interpretation, and writing of the manuscript. JAO contributed to the study design, interpretation, and writing of the manuscript.

\section{Conflicts of Interest}

None declared.

\section{Multimedia Appendix 1}

Calculation of patients cost for videoconferencing and standard consultations (in Norwegian kroner and Euro).

[PDF File (Adobe PDF File), 228KB-Multimedia Appendix 1]

\section{References}

1. Ministry of Health and Care Services. 2011 Apr 8. Meld. St. 16 (2010-2011). Report to the Storting (white paper). Summary — National Health and Care Services Plan URL: https://www.regjeringen.no/en/dokumenter/meld.-st.-16-2010-2011/ id639794/) [accessed 2018-01-03] [WebCite Cache ID 75V2S2LXZ]

2. Patient travels. 2018. Compensation of patient travels URL: https://helsenorge.no/rettigheter/pasientreiser/ reimbursement-of-patient-travel [accessed 2018-03-20] [WebCite Cache ID 75VyvDtdT]

3. The Norwegian Directorate of Health. 2015. Data from the specialist health services (Samdata 2014) URL: https:/ /helsedirektoratet.no/publikasjoner/samdata-spesialisthelsetjenesten [accessed 2017-01-17] [WebCite Cache ID 75VyIedh4] 
4. Pastora-Bernal JM, Martín-Valero R, Barón-López FJ, Estebanez-Pérez MJ. Evidence of benefit of telerehabitation after orthopedic surgery: a systematic review. J Med Internet Res 2017 Dec 28;19(4):e142 [FREE Full text] [doi: 10.2196/jmir.6836] [Medline: 28455277]

5. Bashshur RL, Shannon G, Krupinski EA, Grigsby J. Sustaining and realizing the promise of telemedicine. Telemed J E Health 2013 May;19(5):339-345 [FREE Full text] [doi: 10.1089/tmj.2012.0282] [Medline: 23289907]

6. Jarvis-Selinger S, Chan E, Payne R, Plohman K, Ho K. Clinical telehealth across the disciplines: lessons learned. Telemed J E Health 2008 Sep;14(7):720-725. [doi: 10.1089/tmj.2007.0108] [Medline: 18817503]

7. Steel K, Cox D, Garry H. Therapeutic videoconferencing interventions for the treatment of long-term conditions. J Telemed Telecare 2011;17(3):109-117. [doi: 10.1258/jtt.2010.100318] [Medline: 21339304]

8. Haukipuro K, Ohinmaa A, Winblad I, Linden T, Vuolio S. The feasibility of telemedicine for orthopaedic outpatient clinics--a randomized controlled trial. J Telemed Telecare 2000;6(4):193-198. [doi: 10.1258/1357633001935347] [Medline: 11027118]

9. Couturier P, Tyrrell J, Tonetti J, Rhul C, Woodward C, Franco A. Feasibility of orthopaedic teleconsulting in a geriatric rehabilitation service. J Telemed Telecare 1998;4(Suppl 1):85-87. [doi: 10.1258/1357633981931597] [Medline: 9640749]

10. Aarnio P, Lamminen H, Lepistö J, Alho A. A prospective study of teleconferencing for orthopaedic consultations. J Telemed Telecare 1999;5(1):62-66. [doi: 10.1258/1357633991932405] [Medline: 10505371]

11. Vuolio S, Winblad I, Ohinmaa A, Haukipuro K. Videoconferencing for orthopaedic outpatients: one-year follow-up. J Telemed Telecare 2003;9(1):8-11. [doi: 10.1258/135763303321159620] [Medline: 12641886$]$

12. Caffery LJ, Taylor M, North JB, Smith AC. Tele-orthopaedics: a snapshot of services in Australia. J Telemed Telecare 2017 Dec;23(10):835-841. [doi: 10.1177/1357633X17732800] [Medline: 28950754]

13. Buvik A, Bugge E, Knutsen G, Småbrekke A, Wilsgaard T. Quality of care for remote orthopaedic consultations using telemedicine: a randomised controlled trial. BMC Health Serv Res 2016 Dec 8;16:483 [FREE Full text] [doi: 10.1186/s12913-016-1717-7] [Medline: 27608768]

14. Sharareh B, Schwarzkopf R. Effectiveness of telemedical applications in postoperative follow-up after total joint arthroplasty. J Arthroplasty 2014 May;29(5):918-922. [doi: 10.1016/j.arth.2013.09.019] [Medline: 24342278]

15. Buvik A, Bugge E, Knutsen G, Småbrekke A, Wilsgaard T. Patient satisfaction with remote orthopaedic consultation by using telemedicine: a randomised controlled trial. J Telemed Telecare 2018 Jan 1:1357633X18783921. [doi: 10.1177/1357633X18783921] [Medline: 29973130]

16. Sathiyakumar V, Apfeld JC, Obremskey WT, Thakore RV, Sethi MK. Prospective randomized controlled trial using telemedicine for follow-ups in an orthopedic trauma population: a pilot study. J Orthop Trauma 2015 Mar;29(3):e139-e145. [doi: 10.1097/BOT.0000000000000189] [Medline: 24983434]

17. Jacklin PB, Roberts JA, Wallace P, Haines A, Harrison R, Barber JA, Virtual Outreach Project Group. Virtual outreach: economic evaluation of joint teleconsultations for patients referred by their general practitioner for a specialist opinion. Br Med J 2003 Jul 12;327(7406):84 [FREE Full text] [doi: 10.1136/bmj.327.7406.84] [Medline: 12855528]

18. McGill A, North J. An analysis of an ongoing trial of rural videoconference fracture clinics. J Telemed Telecare 2012 Dec;18(8):470-472. [doi: 10.1258/jtt.2012.gth110] [Medline: 23209275]

19. Rowell PD, Pincus P, White M, Smith AC. Telehealth in paediatric orthopaedic surgery in Queensland: a 10-year review. ANZ J Surg 2014 Dec;84(12):955-959. [doi: 10.1111/ans.12753] [Medline: 25040240]

20. Baruffaldi F, Giangiacomo L, Paltrinieri A, Toni A. Videoconferencing for distance training in orthopaedics. J Telemed Telecare 2003;9(4):241-242. [doi: 10.1258/135763303322225607] [Medline: 12952698]

21. Engle X, Aird J, Tho L, Bintcliffe F, Monsell F, Gollogly J, et al. Combining continuing education with expert consultation via telemedicine in Cambodia. Trop Doct 2014 Apr;44(2):62-68. [doi: 10.1177/0049475513515654] [Medline: 24322763]

22. Zanaboni P, Wootton R. Adoption of telemedicine: from pilot stage to routine delivery. BMC Med Inform Decis Mak 2012;12:1 [FREE Full text] [doi: 10.1186/1472-6947-12-1] [Medline: 22217121]

23. Scott Kruse C, Karem P, Shifflett K, Vegi L, Ravi K, Brooks M. Evaluating barriers to adopting telemedicine worldwide: a systematic review. J Telemed Telecare 2018 Jan;24(1):4-12 [FREE Full text] [doi: 10.1177/1357633X16674087] [Medline: 29320966]

24. Flodgren G, Rachas A, Farmer AJ, Inzitari M, Shepperd S. Interactive telemedicine: effects on professional practice and health care outcomes. Cochrane Database Syst Rev 2015;9:CD002098. [doi: 10.1002/14651858.CD002098.pub2] [Medline: 26343551]

25. Bergmo TS. How to measure costs and benefits of eHealth interventions: an overview of methods and frameworks. J Med Internet Res 2015;17(11):e254 [FREE Full text] [doi: 10.2196/jmir.4521] [Medline: 26552360]

26. Drummond MF, Sculpher MJ, Claxton K, Stoddart GL, Torrance GW. Methods For The Economic Evaluation Of Health Care Programmes. Oxford: Oxford University Press; Nov 24, 2015:464.

27. The Norwegian Directorate of Health. 2012 Nov 2. Economic evaluation of health services - A guide URL: https:/ /helsedirektoratet.no/Lists/Publikasjoner/Attachments/624/Okonomisk-evaluering-av-helsetiltak-IS-1985.pdf [accessed 2018-01-17] [WebCite Cache ID 75V1jGkcx]

28. Drummond M, Manca A, Sculpher M. Increasing the generalizability of economic evaluations: recommendations for the design, analysis, and reporting of studies. Int J Technol Assess Health Care 2005;21(2):165-171. [Medline: 15921055] 
29. Patient Travels. 2018. User fees and rates URL: https://helsenorge.no/rettigheter/pasientreiser/rettigheter/egenandel-og-satser [accessed 2018-03-20] [WebCite Cache ID 75V0ynUwS]

30. Wisløff T, Hagen G, Hamidi V, Movik E, Klemp M, Olsen JA. Estimating QALY gains in applied studies: a review of cost-utility analyses published in 2010. Pharmacoeconomics 2014 Apr;32(4):367-375 [FREE Full text] [doi: 10.1007/s40273-014-0136-z] [Medline: 24477679]

31. Dolan P. Modeling valuations for EuroQol health states. Med Care 1997 Nov;35(11):1095-1108. [Medline: 9366889]

32. Ohinmaa A, Vuolio S, Haukipuro K, Winblad I. A cost-minimization analysis of orthopaedic consultations using videoconferencing in comparison with conventional consulting. J Telemed Telecare 2002;8(5):283-289. [doi: 10.1177/1357633X0200800507] [Medline: 12396857]

33. Wan AC, Gul Y, Darzi A. Realtime remote consultation in the outpatient clinic--experience at a teaching hospital. J Telemed Telecare 1999;5(Suppl 1):S70-S71. [Medline: 10534849]

34. Wallace P, Haines A, Harrison R, Barber J, Thompson S, Jacklin P, Virtual Outreach Project Group. Joint teleconsultations (virtual outreach) versus standard outpatient appointments for patients referred by their general practitioner for a specialist opinion: a randomised trial. Lancet 2002 Jun 8;359(9322):1961-1968. [Medline: 12076550]

35. Benger JR, Noble SM, Coast J, Kendall JM. The safety and effectiveness of minor injuries telemedicine. Emerg Med J 2004 Jul;21(4):438-445 [FREE Full text] [Medline: 15208226]

36. Brennan JA, Kealy JA, Gerardi LH, Shih R, Allegra J, Sannipoli L, et al. Telemedicine in the emergency department: a randomized controlled trial. J Telemed Telecare 1999;5(1):18-22. [doi: 10.1258/1357633991932342] [Medline: 10505365]

37. Tachakra S, Loane M, Uche CU. A follow-up study of remote trauma teleconsultations. J Telemed Telecare 2000;6(6):330-334. [doi: 10.1258/1357633001936003] [Medline: 11265101]

38. Wallace P, Barber J, Clayton W, Currell R, Fleming K, Garner P, et al. Virtual outreach: a randomised controlled trial and economic evaluation of joint teleconferenced medical consultations. Health Technol Assess 2004 Dec;8(50):1-106 [FREE Full text] [Medline: $\underline{15546515]}$

39. Olsen JA, Richardson J. Production gains from health care: what should be included in cost-effectiveness analyses? Soc Sci Med 1999 Jul;49(1):17-26 [FREE Full text] [Medline: 10414837]

40. Wootton R, Bloomer SE, Corbett R, Eedy DJ, Hicks N, Lotery HE, et al. Multicentre randomised control trial comparing real time teledermatology with conventional outpatient dermatological care: societal cost-benefit analysis. Br Med J 2000 May 6;320(7244):1252-1256 [FREE Full text] [Medline: 10797038]

41. Abelsen B, Gaski M, Pedersen EH, Skipperud M. [Is decentralisation of specialised healthcare beneficial in social and financial terms?]. Tidsskr Nor Laegeforen 2004 May 6;124(9):1256-1259 [FREE Full text] [Medline: 15131710]

42. Whitten P, Adams I. Success and failure: a case study of two rural telemedicine projects. J Telemed Telecare 2003;9(3):125-129. [doi: 10.1258/135763303767149906] [Medline: 12877772]

43. Yellowlees PM. Successfully developing a telemedicine system. J Telemed Telecare 2005 Oct;11(7):331-335. [doi: 10.1258/135763305774472024] [Medline: 16238833]

44. Reardon T. Research findings and strategies for assessing telemedicine costs. Telemed J E Health 2005 Jun;11(3):348-369. [doi: $10.1089 /$ tmj.2005.11.348] [Medline: 16035931$]$

\section{Abbreviations}

GEE: generalized estimating equation

GP: general practitioner

QALY: quality-adjusted life year

RCT: randomized controlled trial

RMC: Regional Medical Center

UNN: University Hospital of North Norway

Edited by G Eysenbach; submitted 19.06.18; peer-reviewed by Y Peng, P Haubruck, J Walsh, T Jiang; comments to author 06.10.18,
revised version received 22.11.18; accepted 09.12.18; published 19.02.19
Please cite as:
Buvik A, Bergmo TS, Bugge E, Smaabrekke A, Wilsgaard T, Olsen JA
Cost-Effectiveness of Telemedicine in Remote Orthopedic Consultations: Randomized Controlled Trial
J Med Internet Res $2019 ; 21(2):$ e11330
URL: $\underline{\text { http://www.jmir.org/2019/2/e11330/ }}$
doi: $\underline{10.2196 / 11330}$
PMID: $\underline{30777845}$


(C)Astrid Buvik, Trine S Bergmo, Einar Bugge, Arvid Smaabrekke, Tom Wilsgaard, Jan Abel Olsen. Originally published in the Journal of Medical Internet Research (http://www.jmir.org), 19.02.2019. This is an open-access article distributed under the terms of the Creative Commons Attribution License (https://creativecommons.org/licenses/by/4.0/), which permits unrestricted use, distribution, and reproduction in any medium, provided the original work, first published in the Journal of Medical Internet Research, is properly cited. The complete bibliographic information, a link to the original publication on http://www.jmir.org/, as well as this copyright and license information must be included. 